\title{
Performance Enhancement of Evaporative Cooling by using Bamboo
}

\author{
Shoeb J. Inamdar, Akshay Junghare Parimal Kale
}

\begin{abstract}
In daily life Air-conditioning plays an essential role in ensuring human thermal comfort. The commercially used cooling systems are intensively power consuming. So that it is necessary to save the energy in air conditioning. Among all of them the evaporative cooling techniques is well known which gives better result in saving energy and it is environmental friendly techniques. Evaporative cooling uses the fact that the water will absorb a relatively large amount of heat in order to evapor ate. The temperature of dry air will dropped because of phase change water into water vapors. Evaporative cooling requires abundant water and it works best when relative humidity is low. Evaporative cooling will be done using three methods direct evaporativ e cooling, Indirect Evaporative cooling, combined direct-indirect evaporative cooling.

The main aim of this paper is to make comfort condition in terms of Temperature and Humidity and to minimize the water consumption. In this paper at a place of dry grass or cooling pads we are using hollow bamboo as fluid conduit. In hollow bamboo water continuously flows without any restriction. Some slits or holes are provided on the bamboo to enable the water and air contact and ease the evaporative action after CFD flow simulation. After providing such geometry of contact the evaporation comes to optimism and the water consumption as well as humidity is reduced, the continuous flow of water inside hollow bamboo reduce the contact time of water with air. Due to this effect the humidity of air is comparatively less than direct contact evaporative cooler, also reduces the water consumption. This type of evaporative cooler is designed to facilitate efficient evaporation of the water and circulation of cooled air.
\end{abstract}

Keywords : Evaporation, Humidity, Bamboo, Air conditioning, $C F D$

\section{INTRODUCTION}

Cooling according to human comfort is normally done using AC and evaporative cooler. In evaporative cooler water consumption per hr. is very high in summer availability of water is problem so it is necessary to study and do research on the topic of evaporative cooling in order to make it more economical and efficient. There are mainly two basic types of evaporative cooling systems are present namely direct and indirect evaporative cooling systems. In direct evaporative cooling system the air passes straight across the humidifier into the cooling chamber, while in an indirect evaporative cooling system the $a$ ir is first pre-cooled with heat

Revised Manuscript Received on July 22, 2019.

Shoeb J. Inamdar, Assistant Professor, Department of Mechanical Engineering, H.V.P.M's COET, Amravati, India

Akshay Junghare, U.G Student, Department of Mechanical Engineering, H.V.P.M's COET, Amravati, India

Parimal Kale, U.G Student, Department of Mechanical Engineering, H.V.P.M's COET, Amravati, India

exchangers before passing it through the cooling pad or vice versa depending on the purpose of cooling

The principal of direct evaporative cooling is base on phase change of matter from liquid state to gas by absorbing heat from surrounding which is air in cooler .In case of evaporative cooler air is flow over dry grass which contain water over it which absorb heat from incoming hot air, in this case water absorbed heat of hot air and also uses self heat and get evaporate will doing so water and air both get cooled due to loss of heat of both water and air. After some time water is reach to constant temper ature then all heat of evaporation is absorbed from incoming hot air and cooling rate of air increase. In evaporative cooling air is cooled with humidification means moisture content of air also increases. The process is adiabatic in direct evaporative cooling and as total saturation of the air is not possible, $100 \%$ cooling cannot be achieved.

Then again two basic types of direct evaporative cooling system are active and passive direct evaporative cooling systems. An active evaporative cooling system uses system of fans or blowers to drive the ambient air through the wet pad into the system. This system can function against high static pressure

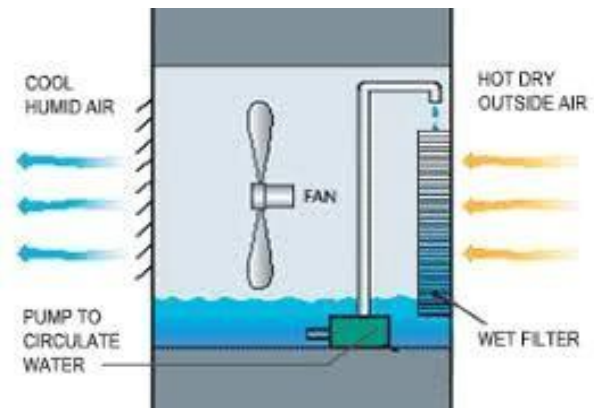

Fig. 1. Evaporative Cooling

In this experimentation we reduced the water consumption of evaporative cooler by replacing dry grass and cooling pads we used hallow bamboo. All node of bamboo were removed to make it hallow though out and to act as fluid conduit. Water is allowed to flow on the inner surface of bamboo, bamboo is having holes on its surface. The holes are provided to enable the air and water contact and to cause the evaporative action. Hole geometry is selected after the flow simulation in CFD. These holes maintain proper airflow inside the bamboo which is virtually shown by CFD. by using structure of bamboo we tried to reduce contact time and contact area of a water and air with each

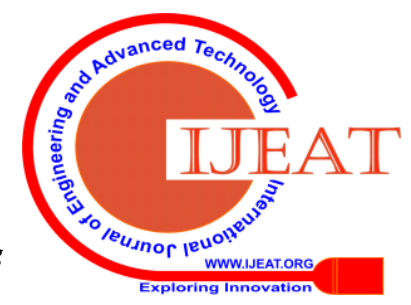


other due to this humidity of air is reduced which in turn causes the reduction in water consumptions it also reduce the feeling of suffocation due to undesired increase in humidity in the air.

Bamboo is widely available in all regions and it is eco friendly. As compare to dry grass life of bamboo is high in water. Thermal conductivity of bamboo various from 0.12 to $0.38 \mathrm{~W} / \mathrm{m}-\mathrm{k}$ with respective density.
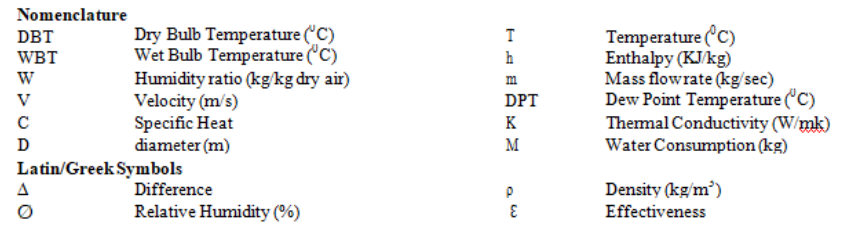

\subsection{Technical Concept Of Evaporative Cooling}

Initially the air is taken at ambient conditions then the air comes in contact with the water provided on the surface. The heat content in the air and water causes the evaporative action and as a result some fraction of water gets evaporated by absorbing the latent heat of evaporation and the air gets cooled and water also gets cooled due to evaporation on surface.

The maximum temp. to which the water can be cooled is the DPT of incoming air. Once the water is cooled to the DPT of air the further cooling of water is stopped and then onwards the total heat of evaporation is absorbed from the incoming air as a result of which the DBT of air decreases. The WBT of air remains almost constant even after the addition of humidity because the volume of air decreases on cooling and the same humidity is adjusted in the relative humidity.

\subsection{Thermo physical properties of bamboo}

According to previous research approximately 148 species in 29 genera of bamboo are thought to found in India, out of which there are 3 large genera namely the Bambusa, the Dendrocalamus, and the Ochlandra with more than 10 species each. These three genera represent about $45 \%$ of the total bamboo species found throughout India. On the other hand, there are some genera which are represented by only one species like Sarocalamus, Ampelocalamus, etc. these all different kind of bamboo species have their own thermo physical properties. So some general thermo physical properties of bamboo are as follows:

1. Thermal conductivity of Bamboo varies from 0.12 to $0.38 \mathrm{~W} / \mathrm{m}-\mathrm{K}$ and it increases with increase in density

2. Specific heat capacity of raw bamboo increases with increase in temperature.

3. The thermal conductivity \& diffusivity of bamboo is not constant along the radial direction

4. Engineered bamboo composite have a same or lower thermal conductivity in comparison with wood of same density

\section{TEST BENCH}

\subsection{Experimental setup}

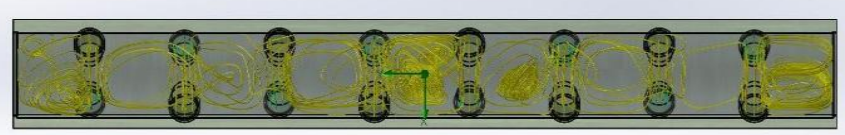

Fig. 2. Initial Bamboo Geometry

The Fig. 2 shows the initial flow geometry selected for evaporative cooling. As can be seen from the flow pattern the inlet and outlet holes are provided in front of each other as a result the major portion of the air does not come in contact with water. The large proportion of the incoming air gets directly impelled towards the outlet hole due to induced pressure draught of the fan. the air does not get swirled in laminar pattern around the water flowing on inner surface of bamboo as a result it can be concluded that proper evaporative action will not be obtained here, Hence this design is not finalized.

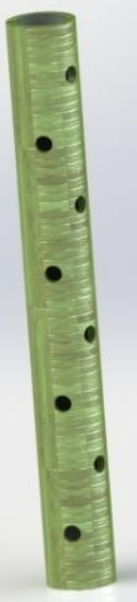

Fig. 3. Final Bamboo Geometry

Fig. 3 shows the final geometry of bamboo, as can be seen the drawback in the previous design been faced was of air left untreated from successive outlet. Here we can see that the holes are so provided that the air enters tangentially and making a laminar pattern inside. This laminar pattern of air comes in contact with the inner surface water of bamboo causing their the evaporative action. Air after evaporative cooling becomes cold as a result air will tend to settle downward and hence the outlet hole is provided at certain vertical depth. The air in this pattern does not causes turbulence as a result the setup lacks vibration. Turbulent mass exchange also causes the rise in temperature which is avoided here completely.

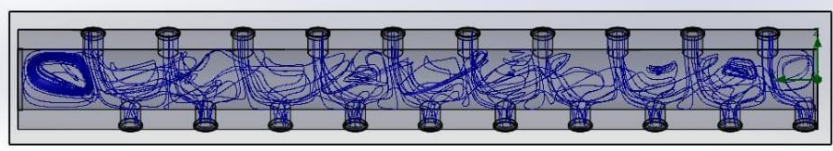

Fig. 4 Flow simulation through final geometry 
As can be seen from the Fig. 4 the air flows in laminar pattern by sticking to the inner surface of bamboo and causes the optimum time and area of contact with water. Air gets swirled and after cooling gets exit from the next succeeding hole and in this way this flow geometry is found to be quite suitable.

This pattern of grooves is provided on bamboos and then they are allowed to act as water conduit in evaporative cooler. Total 13 bamboos has been provided whose dimensions and specifications are mentioned below.

\subsubsection{Dimensions}

Dimensions of equipment

$$
\begin{aligned}
& \text { - } \quad \text { Length }=21 \text { inch } \\
& \text { - } \quad \text { Hidth }=15 \text { inch } \\
& \text { - } \quad \text { Circulating pump }=35 \text { inch } \\
& \text { - } \\
& \text { Sump capacity }=46 \text { Lit }
\end{aligned}
$$

Dimensions of bamboo

- $\quad$ Height $=650 \mathrm{~mm}$

- $\quad$ Outer diameter $=80 \mathrm{~mm}$

- $\quad$ Inner diameter $=65 \mathrm{~mm}$

- $\quad$ Number of holes $=16$

- Hole diameter $=20 \mathrm{~mm}$

\subsection{Experimental process}

1. Water is circulated through the system by circulating pump.

2. Each Bamboo is provided with individual inlet with constant mass flow rate.

3. All the temperatures are recorded at fixed interval of time.

\section{OBSERVATION}

3.1 Initial conditions

1. Dry bulb temperature (D.B.T.) $=350 \mathrm{C}$

2. Wet bulb temperature (W.B.T.) $=270 \mathrm{C}$

3. Relative humidity $(\varnothing)=52 \%$

3.2 Observation table

Table 1. Observation Table for Bamboo Evaporative cooler

\begin{tabular}{|l|l|l|l|l|}
\hline $\begin{array}{l}\text { Time } \\
(\mathrm{min})\end{array}$ & $\begin{array}{l}\text { D.B.T. } \\
(\text { 0C) }\end{array}$ & $\begin{array}{l}\text { W.B.T. } \\
(\text { (C) }\end{array}$ & $\begin{array}{l}\text { Sump } \\
\text { temp. }\end{array}$ & $\begin{array}{l}\text { Bamboo } \\
\text { temp. (0C) }\end{array}$ \\
\hline 10 & 32.1 & 28.0 & 25.1 & 25.4 \\
\hline 20 & 30.2 & 27.6 & 24.3 & 25.2 \\
\hline 30 & 29.6 & 27.3 & 23.3 & 23.0 \\
\hline 40 & 28.9 & 27.2 & 22.5 & 22.9 \\
\hline 50 & 28.3 & 27.1 & 22.0 & 22.7 \\
\hline 60 & 27.9 & 27.2 & 22.0 & 22.4 \\
\hline 70 & 27.2 & 27.1 & 22.0 & 22.3 \\
\hline 80 & 27.9 & 27.1 & 22.1 & 22.3 \\
\hline
\end{tabular}

As visible from the table that system achieves the steady state after 50 mins. Hence the process of evaporative cooling is plotted on the psychrometric chart as a final process 1-2.

The entire process takes place by keeping the one time processing of air as the cooling equipment was kept outside the room. The steady state is reached after $50 \mathrm{~min}$. and that forms the reference of further calculations.

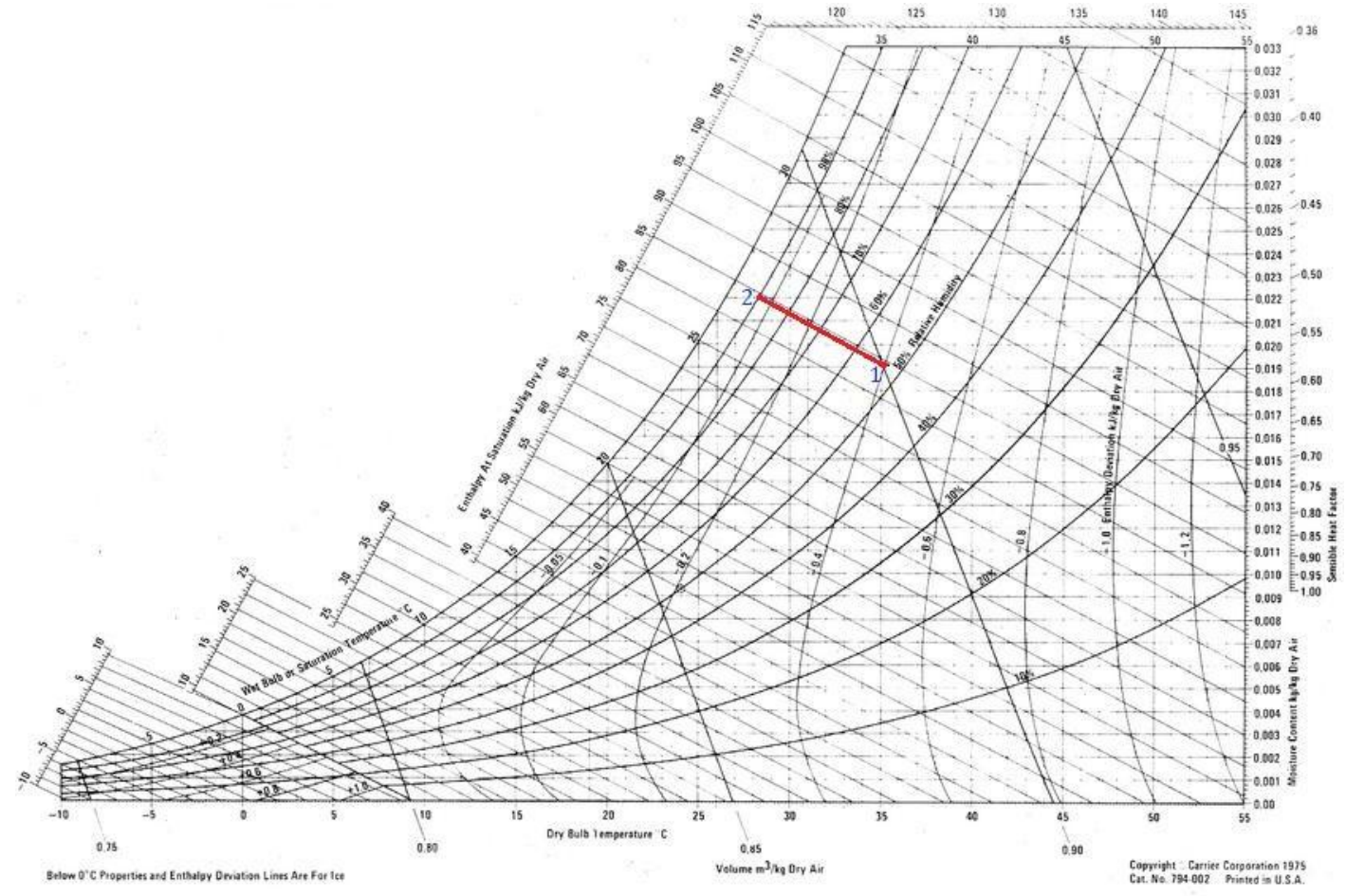

Reproduced courtesy of Carrier Corporation

Fig. 5. Evaporative cooling Process 1-2 on psychometric chart 


\subsection{Sample Calculation:}

Water consumption

Humidity gain $=$ Sp. Humidity at pt. $2-$ Sp. Humidity at 1

$=0.022-0.019$

$=0.003 \mathrm{~kg} / \mathrm{kg}$ Air

Now,

Mass flow rate of air $=$ density $\times$ velocity of air $\times$ area

$=1.11 \times 5.6 \times(3.14 / 4) \times 0.381 \times 0.381$

$=0.708 \mathrm{~kg} / \mathrm{sec}$

Water consumption $=$ humidity gain $\times$ mass flow rate of air $=0.003 \times 0.708$

$=0.00212 \mathrm{~kg} / \mathrm{sec}$

Water consumption after steady state

$=0.00212 \times 50 \times 60$

$=6.3 \mathrm{~kg} / \mathrm{h}$

- $\quad$ Condition of air when cooling pad is used

$\begin{array}{llll} & & \text { Initial } & \text { Final } \\ \text { 1. } & \text { D.B.T. } & 350 \mathrm{C} & 260 \mathrm{C} \\ \text { 2. } & \text { W.B.T. } & 270 \mathrm{C} & 28.50 \mathrm{C} \\ 3 . & \varnothing & 52 \% & 90 \%\end{array}$

Hence from psychrometeric chart water consumption $=12.74 \mathrm{~kg} / \mathrm{hr}$

\section{ANALYSIS AND RESUlt}

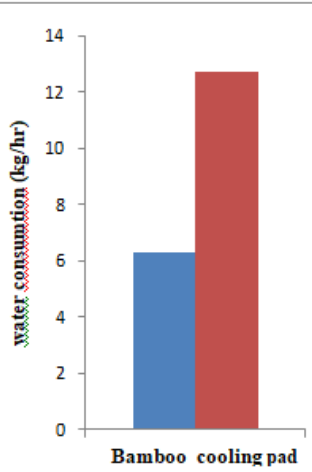

Fig. 6. Water consumption Bamboo Vs Cooling pad

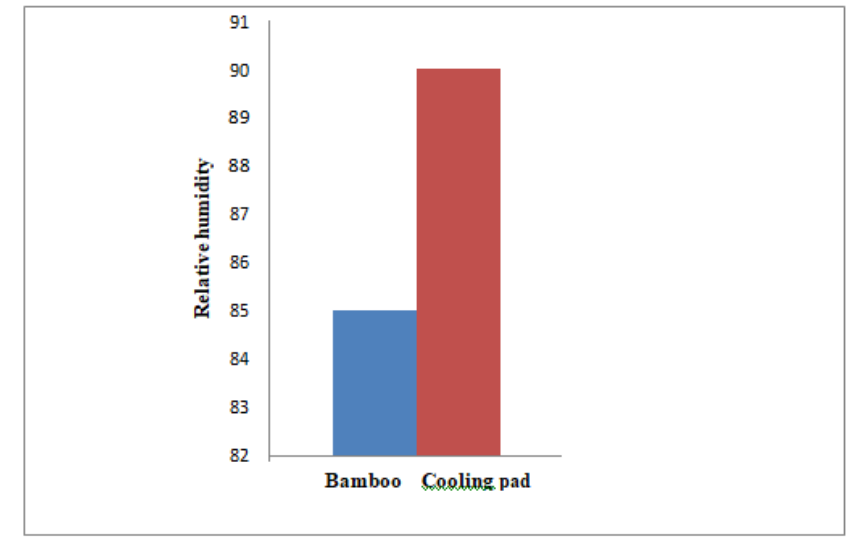

Fig. 7. Relative Humidity Graph Bamboo Vs Cooling Pad

As can be seen from the graph above Fig. $6 \&$ Fig. 7 the water consumption of cooling pad is high as a result it leads to the higher relative humidity. The comfort range of relative humidity is between $70-90 \%$. The cooling pads consume almost double the water as compared to the design proposed of bamboo. The surface area of contact and time of contact between air and water is high in case of cooling pads as a result it evaporates more water and hence the water consumption increases. The time and area of contact in case of bamboo design is relatively low as a result the water consumption decreases but the relative humidity is achieved in comfort zone i.e $85 \%$.

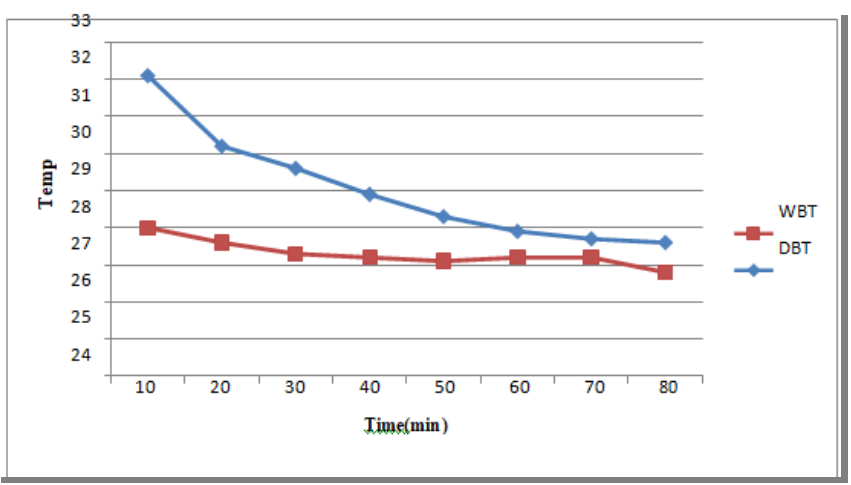

Fig. 7. Temp. Vs Time Plot

Fig. 7 Shows the variation of Temp. with time. Initially the air is taken at initial conditions specified. the air comes in contact with the water and causes the evaporative action and as a result some fraction of water gets evaporated by absorbing the latent heat of evaporation and the air gets cooled and water also gets cooled due to evaporation on surface.

The maximum temp. to which the water can be cooled is the DPT of incoming air. Once the water is cooled to the DPT of air the further cooling of water is stopped and then onwards the total heat of evaporation is absorbed from the incoming air as a result of which the DBT of air decreases. The WBT of air remains almost constant even after the addition of humidity because the volume of air decreases on 
cooling and the same humidity is adjusted in the relative humidity.

\section{EFFECTIVENESS OF EVAPORATIVE COOLER}

The effectiveness of evaporative cooler is given by.

$$
\begin{aligned}
\mathcal{E} & =\left(\frac{T_{d b, \text { in }}-T_{d b, \text { out }}}{T_{d b, \text { in }}-T_{w b, i n}}\right) \times 100 \\
& =\left(\frac{35-29}{35-27}\right) \times 100 \\
& =75 \%
\end{aligned}
$$

\section{CONCLUSION}

The study is performed on the evaporative cooler made of bamboo and after studying several parameters and correlating them some conclusions are made as follows.

1. The water consumption is decreased to almost half of the cooling pad when bamboo with such flow geometry is used.

2. The DBT and RH remains in comfort zone with less water consumption.

3. Life of the equipment is long as compared to traditional setups.

\section{REFERENCES}

1. Long Jibo, Thermal and Moisture Stress Analysis of Bamboo Buildings Based on Heat and Mass Transfer Method of Porous Medium [D].

2. ISO 15148:2002(E): Hygrothermal performance of building materials and products - Determination of water absorption coefficient by partial immersion[S].

3. Zhao X, Li JM, Riffat SB. Numerical study of a novel counter-flow heat and mass exchanger for dew point evaporative cooling. Appl Therm Eng 2008;28:1942-51.

4. Chen PL. Discussion on the application prospect of indirect evaporative cooling in China. HVAC 1988;2:24-9 [in Chinese].

5. Chen PL. The application of indirect evaporative cooling in air conditioning. Refrigeration Technology 1988;3:1 -8 [in Chinese].

6. Chen PL, Qin H, Huang YJ, Wu H, Blumstein C. The energy-saving potential of precooling incoming outdoor air by indirect evaporative cooling. ASHRAE Trans 1993;99(Pt 1).

7. Chen PL. Feasibility studies on indirect evaporative cooling in China. HVAC 1994;5:3-5 [in Chinese].

8. Chen PL. Applications of the evaporative cooling techniques in moderate and humid climates. HVAC 1995;4:3-8 [in Chinese].

9. Tan ZH, Qiang TW, Shen HG. Application research of direct evaporative cooling air conditioner in industry bui lding. Refrigeration and Air-conditioning 2006;2:63-6 [in Chinese].

10. Huang JG, Zhao LP. Feasibility research of evaporative cooling air-conditioning in application to iron and steel enterprises. Refrigeration and Air-conditioning 2007;21(4):81-4 [in Chinese].

11. Meng QL, Li JC, Wang ZW, Tao J, Cai N. Climatic resources in Guangzhou and the application of passive evaporative cooling. Tropical Geography 1998;18(2):168-71 [in Chinese].

12. Wang CY, Cao W, Li BM, Shi ZX, Geng A. A fuzzy mathematical method to evaluate the suitability of an evaporative pad cooling system for poultry houses in China. Biosystems Engineering 2008;101:370-5. 